\title{
Isolation and molecular identification of Leishmania (Viannia) peruviana from naturally infected Lutzomyia peruensis (Diptera: Psychodidae) in the Peruvian Andes
}

\author{
J Enrique Perez ${ }^{+}$, Nicolas Veland, Diego Espinosa, Katherine Torres, Elena Ogusuku, \\ Alejandro Llanos-Cuentas, Dionicia Gamboa, Jorge Arévalo
}

Instituto de Medicina Tropical Alexander von Humboldt, Universidad Peruana Cayetano Heredia, Apartado 4314, Lima-100, Perú

Leishmania (Viannia) peruviana was isolated from 1/75 Lutzomyia peruensis captured during May 2006 in an endemic cutaneous leishmaniasis region of the Peruvian Andes (Chaute, Huarochiri, Lima, Peru). Sand fly gut with promastigotes was inoculated into a hamster and the remaining body was fixed in ethanol. L. (Viannia) $s p$. was determined by polymerase chain reaction $(P C R)$, and Leishmania species through molecular genotyping by PCR-restriction fragment length polymorphism analyses targeting the genes $\mathrm{cpb}$ and hsp70, resulting L. (V.) peruviana. The infected sand fly appeared 15 days after the rains finished, time expected and useful real time data for interventions when transmission is occurring.

Key words: Leishmania peruviana - Lutzomyia peruensis - polymerase chain reaction-restriction fragment length polymorphism - Peru

An important step for the incrimmination of Leishmania vectors is the report of naturally infected sand fly species (Killick-Kendrick \& Ward 1981). The proportion of sand flies infected with Leishmania in places frequented by humans is taken into account. Several methods have been applied for this requirement, being the sand fly gut dissection first used, although it is the less productive one because of the low Leishmania infection rate in sand flies (0.001-2.6) (Perez et al. 1994), the requirement of living sand flies and well trained personnel for sand fly gut dissection. To date this technique is still being used with the purpose of isolating the parasite from an individual sand fly. Sand flies can also be cryopreserved in liquid nitrogen to be dissected months later. Young et al. (1987) dissected 18,463 sand flies, obtaining $11(0.059 \%)$ with Leishmania promastigotes in Colombia. In another technique, the whole sand fly body is homogenized in pools of up to 24 individuals and then inoculated into hamsters, where Leishmania infection produces lesions in at least six weeks. Finally, the parasites are isolated by aspiration of the lesions and transferred to culture medium. Using this technique the number of infected sand fly individuals is unknown and it is possible to have a mixture of Leishmania strains in a single pool. Sentinel hamsters have also been used to obtain Leishmania strains from sand flies (Herrer 1982a). The animals are exposed to sand fly bites in en-

Financial support: Fondo Concursable, Vicerrectorado de Investigación, Universidad Peruana Cayetano Heredia, project 70000315 , Directorate-General for Development Cooperation of the Belgian Government (framework agreement 02, Project 95501)

${ }^{+}$Corresponding author: kike@ upch.edu.pe

Received 13 February 2007

Accepted 2 July 2007 demic areas and then aspirates of different parts of the hamster body are taken and inoculated into culture medium to isolate the parasites. Here indeed, the infected sand fly species are unknown. Detection of Leishmania DNA is now a commonly used technique. Sand flies can be preserved dried or frozen and large number of sand flies can be processed individually or in pools. By means of polymerase chain reaction (PCR) it is possible to amplify and detect DNA of less than one Leishmania parasite (Lopez et al. 1993). Leishmania species identification is now done by using specific primers designed for different Leishmania genes currently used as targets for molecular genotyping (Garcia et al. 2004, 2005).

The search for Leishmania vectors in Peru started in the Andes, where the diversity of sand fly species is low (1-6 species in a single valley). Cruzado (1987) reported four specimens of Lutzomyia peruensis infected with Leishmania in La Libertad. Herrer (1982b) obtained two $(2.06 \%)$ isolates of Leishmania sp. from 97 specimens of Lu. peruensis homogenized and inoculated into hamsters, in the Rimac Valley (Lima). Perez et al. (1991) reported two isolations of Leishmania from sand flies, the first (strain IPRN/PE/87/Lp52) by inoculation of pools of homogenized Lu. peruensis $(0.34 \%)$ and the second in a sentinel hamster, in the Huayllacallan Valley (Ancash). The strain Lp52 has been recently identified as L. (Viannia) guyanensis by means of PCR-restriction fragment length polymorphism (RFLP) analyses of kDNA minicircles (kDNAPCR-RFLP) (Callapiña 2001). Perez et al. (1994) worked with pools of 4-10 sand fly individuals for PCR detection of DNA of the L. (Viannia) subgenus, and found two pools of Lu. peruensis $(0.2 \%)$ and six of $L u$. verrucarum $(0.13 \%$ ) positive for $L$. (Viannia) sp. Caceres et al. (2002) in Ayacucho dissected 1849 Lu. ayacuchensis, obtaining five $(0.27 \%)$ positives for Leishmania sp. by PCR, and four of which were cultured and determined as L. peruviana by multilocus enzyme electrophoresis and molecular karyotyping. 
The main goal of the present study was to find infected sand flies when they are most numerous, which is after the rainy period in the Andes, from the end of April to May (Perez et al. 1994), and also to carry out the Leishmania species determination through PCR amplification, followed by PCR-RFLP.

Sand flies for this study were captured in Chaute (Huarochirí, Lima), SL11 ${ }^{\circ} 56.455^{\prime}$ and WL76 ${ }^{\circ} 30.392^{\prime}$, at $2400 \mathrm{~m}$ of altitud, in May 2006, using a Shannon trap with protected human bait from 18:00 to 19:00 (Perez et al. 1988). All sand flies captured were placed in collecting flasks and provided with sugar solution (30\%) in a piece of cotton, and transported to our laboratories in Lima where living sand flies are maintained in a sand fly colony room at constant temperature of $20^{\circ} \mathrm{C}$.

San dfly guts were dissected in saline solution with antibiotics and observed under compound microscope at 400x magnification. A total of 317 female sand flies were dissected in May 2006 (75 of Lu. peruensis and 242 of $\mathrm{Lu}$. verrucarum).

A typical peripylarian infection was detected in a 1/75 Lu. peruensis captured by JE Perez on May 6, 2006. The stomodeal valve and midgut were full of promastigotes and traces of digested blood, the peritrophic membrane was not observed, the pylorus showed pear shaped promastigotes attached to its interior walls and no free promastigotes were observed in the hind gut. The infection was apparently old (6 to 9 days), the infected sand fly was attracted to the human bait, probably to take a bloodmeal. The gut was placed in another drop of saline solution with antibiotics, broken to release the parasites and then inoculated onto 5\% blood agar base biphasic culture medium, and also inoculated onto the hind feet of a golden hamster (Mesocricetus auratus). The rest of the sand fly body (head, thorax, and abdomen) was fixed in absolute ethanol and processed for Leishmania DNA extraction, PCR using the primers MP1-L and MP3-H, which are specific for L. (Viannia) spp. (Arevalo et al. 1993), and molecular genotyping by PCR-RFLP using two different genes as targets, which encode major Leishmania antigens cysteine proteinase B $(c p b)$, and heat shock protein $70(h s p 70)$ (Garcia et al. 2004, 2005).

Although the cultures were heavily contaminated, they were processed for amplification of Leishmania DNA. After seven weeks, the hamster did not show lesion, just a weak swelling and reddish area at the inoculation sites. The abnormal sites were aspirated and this material inoculated into culture medium, and maintained at $23^{\circ} \mathrm{C}$. Leishmania promastigotes were observed on the 3rd day of culture and the strain was coded IPRN/PE/2006/Chaute1.

Leishmania DNA amplification was successful from all materials which include fragments of sand fly body, contaminated culture and the positive culture from hamster lesions. The PCR employed, using the primers MP1-L and MP3-H, showed that the DNA isolated from the strain IPRN/PE/2006/Chaute1 belonged to any of the species belonging to the subgenus L. (Viannia), where the characteristic amplification products of 72 base pair was shown by all materials (Arevalo et al. 1993). This fact was confirmed through a PCR technique using $c p b$ gene (Fig. 1), the species of the subgenus L. (Viannia) including the strain IPRN/PE/2006/Chaute1 shown a similar pattern, a band of $1170 \mathrm{bp}$. The PCR-RFLP technique applied afterwards showed, using two different markers ( $c p b$ and $h s p 70$ ), that the parasite was in fact $L$. (V.) peruviana (Figs 2,3). Using the $c p b$ gene alone, which shows a characteristic pattern for $L$. (V.) braziliensis after the restriction enzyme analysis with Taq1, we obtained a similar pattern to the reference strains L. (V.) peruviana (MHOM/PE/90/HB22) and L. (V.) guyanensis (IPRN/PE/87/Lp52) (Garcia et al. 2005). Using the $h s p 70$ gene as marker, the result is a specific pattern for $L$. (V.) guyanensis, the pattern obtained after the restriction enzyme analysis with BsuRI showed similarity with the reference strains $L$. (V.) peruviana (MHOM/PE/90/HB22) and L. (V.) braziliensis (MHOM/PE/93/LC2177); the identity of these strains was confirmed by Garcia et al. (2004, 2005).

The combination of the presence of $343 \mathrm{bp}$ for the $c p b$ gene band of $L$. (V.) braziliensis, and the absence of a $224 \mathrm{bp}$ for the $h s p 70$ gene band of $L$. (V.) guyanensis, distinguishes $L$. (V.) peruviana from these two species (cf. Garcia et al. 2005).

The isolation of the strain Chaute1 was carried out within the peak season of sand fly abundance, Leishmania infection both of sand flies and humans in Chaute. This situation was previously described by Perez et al. (1994), and it occurs seasonally just after the rains finish in the Andes (late April). The obtention of infected

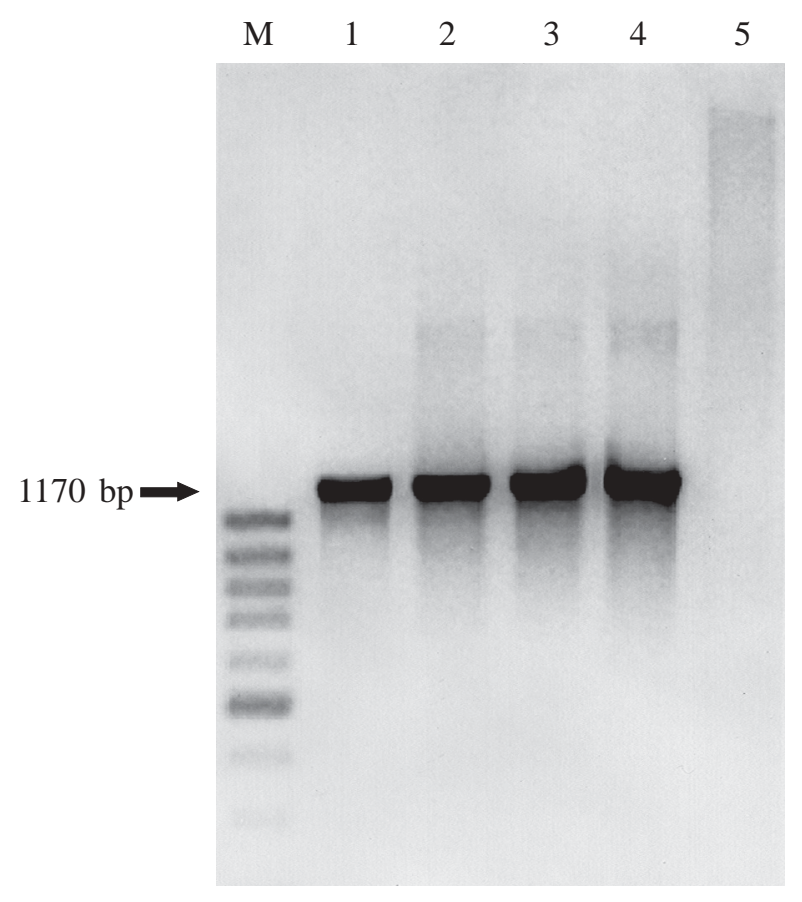

Fig. 1: agarose electrophoresis gel of $c p b$ polymerase chain reaction products. M: 100 bp ladder; 1: IPRN/PE/2006/Chaute1; 2: Leishmania (Viannia) braziliensis (MHOM/PE/93/LC2177); 3: L. (V.) peruviana (MHOM/PE/90/ HB22); 4: L. (V.) guyanensis (IPRN/PE/87/Lp52); 5: negative control. 


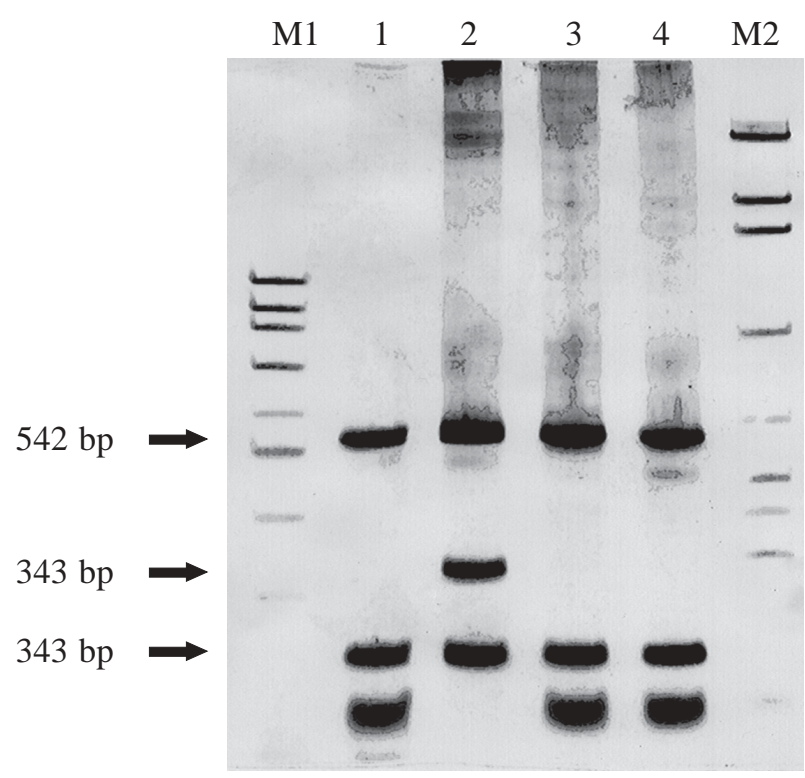

Fig. 2: $c p b$ polymerase chain reaction-restriction fragment length polymorphism analyses patterns (Taq1) after polyacrylamide gel electrophoresis. M1: 100 bp ladder; 1: IPRN/PE/2006/Chaute1; 2: Leishmania (Viannia) braziliensis (MHOM/PE/93/LC2177); 3: L. (V.) peruviana (MHOM/PE/90/HB22); 4: L. (V.) guyanensis (IPRN/PE/87/Lp52); M2: pGEM ladder.

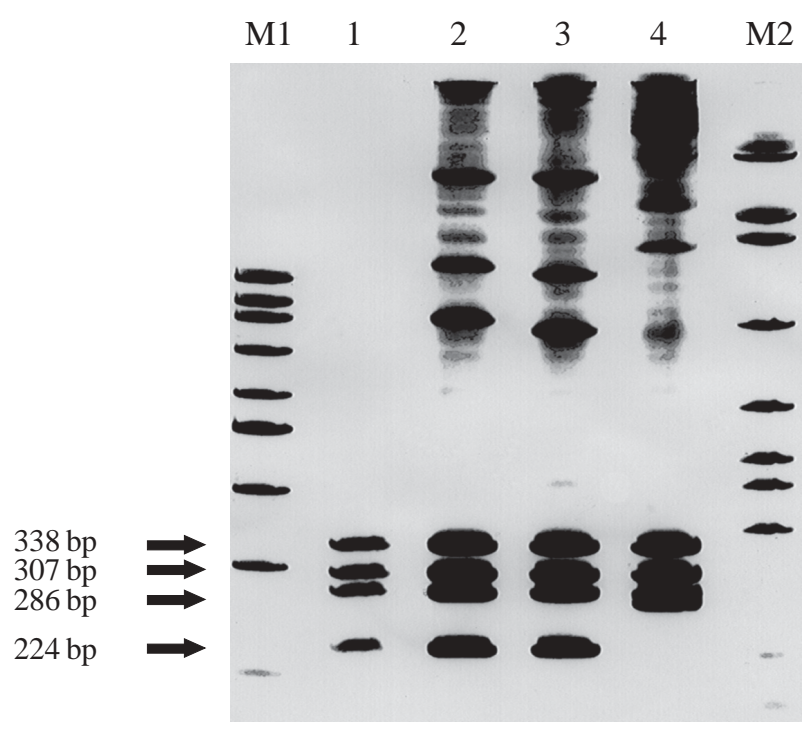

Fig. 3: $h s p 70$ polymerase chain reaction-restriction fragment length polymorphism analyses patterns (BsuRI) after polyacrylamide gel electrophoresis. M1: 100 bp ladder; 1: IPRN/PE/2006/Chaute 1; 2: Leishmania (Viannia) braziliensis (MHOM/PE/93/LC2177); 3: L. (V.) peruviana (MHOM/PE/90/HB22); 4: L. (V.) guyanensis (Lp52); M2: pGEM ladder.

sand flies is more successful on this time of the year in the Andean Leishmania endemic areas. Sand flies are also a nuisance insect, an average of 472 sand fly bitings can be received by night in Chaute in the sand fly peak season.

It is understood that the chance to find naturally infected sand flies with Leishmania is normally very low, but is necessary to obtain living pathogens from sand flies for further studies. It is convenient to determine if the Leishmania strains proceeding from sand flies and animals are the same as those proceeding from humans. Studies like that should be performed with some periodicity as surveillance to detect changes in the genetical patterns (infectivity, virulence) of Leishmania species strains through time in a given endemic area. Leishmania infection rate of animals, which are the source of infection of sand flies, is variable, it is $0.2-2.8 \%$ in wild mice and 2.6-11.9\% in dogs (Llanos-Cuentas et al. 1999). The isolation of the strain Chaute1 represents $1.33 \%$ of the $L u$. peruensis captured in May 2006 in Chaute, the rate found is higher than the records in other Andean areas (Caceres et al. 2002).

L. verrucarum was not found infected with Leishmania in this study, which contrast with the findings of Perez et al. (1994), where six infected individuals were detected by means of PCR. This fact probably correspond to light infections probably missing in the observation under microscope and the fact that PCR technique is much more effective for the detection of early infections and those that may not succeed in the sand fly. This is the main reason why it is highly recommended.

The study of Lu. peruensis becomes relevant. This species coexist with $L u$. verrucarum and both species are vectors of Andean cutaneous leishmaniasis which is caused mainly by $L$. (V.) peruviana. In the Department of Ancash (central Peruvian Andes), L. (V.) guyanensis also affects the human population in the same areas, being the second Leishmania species found in Lu. peruensis (Perez et al. 1994).

Information about infected sand flies can be available in few days combining sand fly gut dissection with PCR detection of Leishmania DNA and Leishmania species identification by PCR-RFLP. Sand fly dissectors should work routinarely closer to PCR procedures equipped with a set of specific primers. The knowledge of the Leishmania and its vector species in a real time can result in appropriate intervention when the transmission is taking place in a given area.

\section{ACKNOWLEDGEMENTS}

To Ana Quispe (Leishmaniosis Working Group, IMTAvH, $\mathrm{UPCH}$ ) for her technical support in Leishmania cultures.

\section{REFERENCES}

Arevalo J, Inga R, Lopez M 1993. PCR detection of Leishmania braziliensis. In DH Persing, TF Smith, FC Tenover, TJ White, Diagnistic Molecular Microbiology, American Society for Microbiology, Washington, p. 456-461.

Caceres A, Villaseca P, DuJardin JC, Bañuls AL, Inga, Lopez M, Arana M, Le Ray D, Arevalo J 2002. Epidemiology of Andean cutaneous leishmaniasis: incrimination of Lutzomyia ayacuchensis (Diptera: Psychodidae) as a vector of Leishmania in geographically isolated, upland valleys of Peru. Am J Trop Med Hyg 70: 607-612.

Cruzado L 1987. Lutzomyia peruensis vector de Leishmania sp. en Pagash, Padai, Otuzco, Peru. Resumenes de Trabajos Cientificos, X Congreso Latinoamericano de Microbiologia, Trujillo, Peru, p. 187. 
Callapiña M 2001. New Strategy for the Study and Structuring of Populations of Leishmania by Means of Analysis of Esquizodemas of Products of Amplification by PCR, MSc Thesis, Universidad Peruana Cayetano Heredia, Lima, 100 pp.

Garcia AL, Kindt A, Bermudez H, Llanos-Cuentas A, De Doncker S, Arevalo J, Quispe KW, DuJardin JC 2004. Culture-independent species typing of Neotropical Leishmania for clinical validation of a PCR-based assay targeting Heat Shock Protein 70 genes. J Clin Microbiol 42: 2294-2297.

Garcia AL, Kindt A, Quispe KW, Bermudez H, Llanos A, Arevalo J, Bañuls AL, De Doncker S, Le Ray D, DuJardin JC 2005. American tegumentary leishmaniasis: antigen-gene polymorphism, taxonomy and clinical pleomorphism. Infect Genet Evol 5: 109-116.

Herrer A 1982a. Empleo del hamster dorado como animal centinela en las localidades donde es endemica la uta (leishmaniasis tegumentaria). Rev Inst Med Trop São Paulo 24: 162-167.

Herrer A 1982b. Lutzomyia peruensis Shannon, 1929, posible vector natural de la uta (leishmaniasis tegumentaria). Rev Inst Med Trop São Paulo 24: 168-172.

Killick-Kendrick R, Ward RD 1981. Ecology of Leishmania. Parasitology 82: 143-152.

Llanos-Cuentas EA, Roncal N, Villaseca P, Paz L, Ogusuku E, Perez JE, Caceres A, Davies CR 1999. Natural infections of
Leishmania peruviana in animals in the Peruvian Andes. Trans $R$ Soc Trop Med Hyg 93: 15-20.

Lopez M, Orrego C, Cangalaya M, Inga R, Arevalo J 1993. Diagnosis of Leishmania via the polymerase chain reaction a simplified procedure for field work. Am J Trop Med Hyg 49: $348-356$

Perez JE, Ogusuku E, Iinga R, Lopez M, Monje J, Paz L, Nieto E, Arevalo J, Guerra H 1994. Natural Leishmania infection of Lutzomyia spp. in Peru. Trans R Soc Trop Med Hyg 88: 161-164.

Perez JE, Villaseca P, Llanos A, Campos M, Guerra H 1988. Tecnicas de muestreo de "titiras" (Lutzomyia spp., Diptera: Psychodidae) utilizados en ambientes altoandinos del Perú. Rev Per Ent 29: 8791.

Perez JE, Villaseca P, Caceres A, Lopez M, Zolessi A, Campos M, Guerra H, Llanos Cuentas A 1991. Leishmania (Viannia) peruviana isolated from the sandfly Lutzomyia peruensis (Diptera: Psychodidae) and sentinel hamster in the Huayllacallan valley (Ancash, Peru). Trans R Soc Trop Med Hyg 85: 60.

Young DG, Morales A, Kreutzer RA, Alexander JB, Corredor A, Tesh RB, Ferro C, Rodriguez C 1987. Isolation of Leishmania braziliensis (Kinetoplastida: Trypanosomatidae) from cryopreserved Colombian sand flies (Diptera: Psychodidae). J Med Ent 24: 588-589. 